\title{
In vivo human lens epithelial cell proliferation on the anterior surface of PMMA intraocular lenses
}

\author{
Milind V Pande, David J Spalton, John Marshall
}

\begin{abstract}
Aims-To study in vivo human lens epithelial cell proliferation on the anterior surface of PMMA implants and its interaction with postoperative blood-aqueous barrier breakdown in eyes undergoing cataract surgery.

Methods-A prospective study was carried out on three consecutive patient cohorts undergoing cataract surgery with intraocular lens implantation using three different surgical techniques which produce different anatomical relations between the implant and lens capsule. Specular microscopy of the anterior implant surface was used to document the natural history, topography, and density of lens epithelial cells and the laser flare and cell meter were used to measure postoperative bloodaqueous barrier breakdown.

Results-All groups showed lens epithelial cell proliferation onto the anterior surface of PMMA implants. This was initiated by and restricted to the region of anterior capsule-implant contact and decreased with the onset of anterior capsular opacification. Significant correlation was found in all groups between lens epithelial cell proliferation and postoperative bloodaqueous barrier breakdown.

Conclusions-Human lens epithelial cell behaviour on PMMA surfaces in vivo differs from that seen in culture studies. Humoral factors in the aqueous, biomaterial properties of the implant, and its anatomical relations with the anterior and posterior lens capsule influence lens epithelial cell behaviour in vivo.

(Br f Ophthalmol 1996; 80: 469-474)
\end{abstract}

Optical clarity of the lens capsule plays a critical role in the visual recovery of patients after cataract surgery. Intraocular lens implantation creates a large surgical wound in the lens which incudes a wound healing response consisting of lens epithelial cell proliferation, migration, and metaplasia. ${ }^{1}$ The construction of the surgical wound and the properties of the implant biomaterial are major factors which can influence these processes. Various surgical techniques ${ }^{2-4}$ and implant designs ${ }^{5-11}$ aimed at reducing the high $(20-50 \%)^{11-13}$ incidence of posterior capsular opacification have met with limited success.

The behaviour of lens epithelial cells in vitro, ${ }^{14-18}$ and in animal models ${ }^{19-21}$ has been studied but their in vivo behaviour in the dynamic environment of the human eye has not been documented. Cellular events on the anterior surface of intraocular lenses can be studied in vivo by specular microscopy and this technique has been used to study the cellular components of the foreign body reaction induced by the implant. ${ }^{22-24}$ In previous reports we have shown that the cellular reaction on the anterior surface of an implant consists of both a foreign body reaction (macrophage response) and a lens epithelial cell reaction. ${ }^{25}$ This paper reports on the postoperative behaviour of lens epithelial cells on the anterior surface of PMMA intraocular lenses implanted with different surgical techniques to assess the natural history, growth patterns, and interaction with postoperative blood-aqueous barrier breakdown.

\section{Material and methods}

This study was approved by the hospital ethics committee and all patients gave informed consent. Ninety two eyes of 84 consecutive patients from the day case waiting lists in three groups of 30,31, and 31 eyes were enrolled in the study. All eyes had age-related cataracts, normal anterior segments apart from cataract, and had no previous intraocular surgery. Uveitis, glaucoma, pseudoexfoliation, concurrent use of topical medications, diabetes, or systemic steroid medication were preoperative exclusion criteria.

The three groups were operated on by three experienced surgeons using their routine techniques for cataract extraction. Group 1 had standardised extracapsular cataract extraction with a linear capsulotomy by surgeon 1 ; group 2 had standardised extracapsular cataract extraction with continuous curvilinear capsulorhexis by surgeon 2; and group 3 had standardised divide and conquer phacoemulsification with continuous curvilinear capsulorhexis by surgeon 3. There was no selection of cases towards any particular technique based on the type of cataract. This design was chosen to eliminate the bias of surgical experience towards a particular technique as the three surgeons involved used their current surgical technique in which they had considerable experience. The three techniques used are briefly outlined below.

EXTRACAPSULAR CATARACT EXTRACTION WITH LINEAR CAPSULOTOMY

This was performed with 120 degree corneal section, linear capsulotomy under Healon, hydrodissection and expression of the nucleus, irrigation aspiration of cortex, in the bag implantation of a $7 \mathrm{~mm}$ biconvex optic, one piece PMMA lens under Healon, anterior capsulectomy, section closure with $10 / 0$ monofilament nylon suture, and Healon removal. 


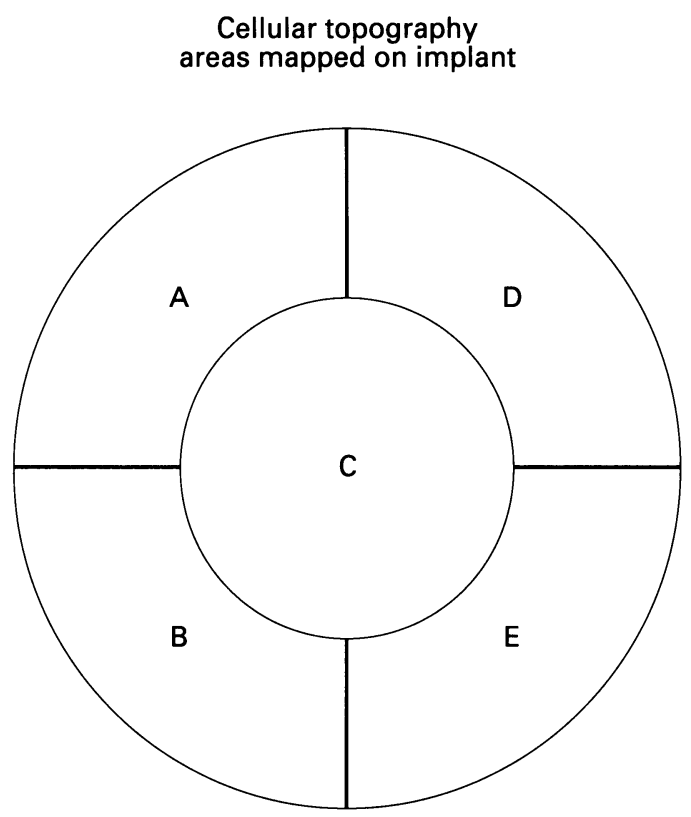

Figure 1 The implant optic was divided into a central area $C$ (circle with half the diameter of the implant optic) and a peripheral area. The peripheral area was further divided into four quadrants $A, B, D, E$.

EXTRACAPSULAR CATARACT EXTRACTION WITH CONTINUOUS CURVILINEAR CAPSULORHEXIS This consisted of 120 degree corneal section, 5-5.5 mm continuous curvilinear capsulorhexis with a Utrata forceps under Healon, hydrodissection and hydroexpression of the nucleus (no relieving incisions to the rhexis were made), irrigation aspiration of cortex, in the bag implantation of a $7 \mathrm{~mm}$ biconvex optic, one piece PMMA lens under Healon, section closure with $10 / 0$ monofilament nylon suture, and Healon removal.

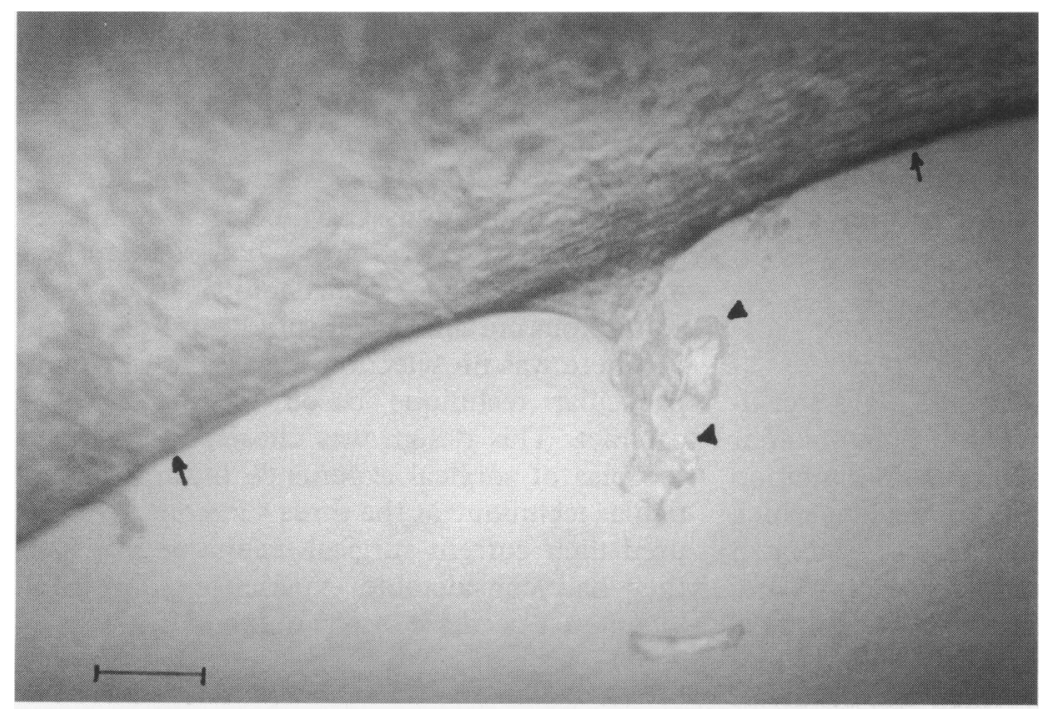

Figure 2 Specular photograph of lens epithelial cells proliferating on to the anterior surface of a PMMA implant from the edge of the anterior capsule (arrows). Lens epithelial cells had processes with interference patterns (arrowheads). Bar $=220 \mu \mathrm{m}$.

Table 1 Criteria for lens epithelial cell density grading

Grade $0 \quad$ No lens epithelial cells

Grade 1 Sheet of cells restricted to 1 quadrant of optic or $<10$ cells

Grade 2 Sheet of cells extending for more than 1 but less than 3 quadrants or between 10-30

Grade 2 cells

Grade 3 Sheet of cells extending for 3 or more quadrants or more than 30 cells
'DIVIDE AND CONQUER' PHACOEMULSIFICATION WITH CONTINUOUS CURVILINEAR CAPSULORHEXIS

A $3.2 \mathrm{~mm}$ wide scleral tunnel incision was made 4.5-5 mm continuous curvilinear capsulorhexis under Healon with Utrata forceps, 'divide and conquer' phacoemulsification of nucleus, irrigation aspiration of cortex, section width enlarged to $5 \mathrm{~mm}$, in the bag implantation of a $5 \times 6 \mathrm{~mm}$ biconvex optic one piece PMMA implant, Healon removal, and tunnel closure with a single 10/0 monofilament nylon suture.

Posterior capsular rupture, zonular dehiscence, severe iris trauma during surgery, and anterior capsular rim tears in the capsulorhexis were surgical exclusion criteria.

A preoperative medication regimen of chloramphenicol eyedrops four times daily for 1 day, cyclopentolate $1 \%$ and phenylephrine $10 \%, 1$ drop every 15 minutes in the hour preceding surgery was used in all cases. Indomethacin $1 \%$ four times daily on the day before surgery was used in group 2 cases only. Balanced salt solution with adrenaline for intraocular irrigation and subconjunctival cefuroxime $125 \mathrm{mg}$ at the end of surgery were used in all cases. No subconjunctival steroids were used in any patient on the study. The common postoperative regimen used was Maxitrol eyedrops (dexamethasone and neosporin) four times daily for the first postoperative week then twice daily for the next 3 weeks. No intraoperative or postoperative nonsteroidal anti-inflammatory medications were used in any case.

Specular microscopy of the anterior implant surface using the Keeler Konan specular microscope or a Zeiss photo slit-lamp was carried out after dilating the pupil with tropicamide and phenylepherine eyedrops on 1 day, 1 week, 1 month, and 3 months postoperatively. The anterior surface of the implant was divided into five regions as shown in Figure 1. These region codes were used to map the topography of lens epithelial cells, anterior capsule-implant touch, and anterior capsular opacification. Cellular density of lens epithelial cells (Fig 2) was graded using the criteria in Table 1. All cases had their implant surface cellular reaction graded by the same observer at all visits.

Anterior chamber flare and cells were measured using the Kowa FC-1000 laser flare meter preoperatively and on 1 day, 1 week, 1 month, and 3 months postoperatively. All laser flare measurements were performed by the same observer about 30 minutes after pupillary dilatation with 1 drop of tropicamide $1 \%$ and phenylepherine $10 \%$. Seven consecutive laser flare readings with background scatter of less than $15 \%$ were taken and the five readings left after discarding the highest and lowest value were averaged to obtain the flare and cell measurement. Laser flare values were expressed in photons $/ \mathrm{ms}$ and anterior chamber cells as number of cells per $0.075 \mathrm{~mm}^{3}$.

\section{STATISTICAL ANALYSIS}

Cellular density grading scores did not have a normal distribution and are presented as 


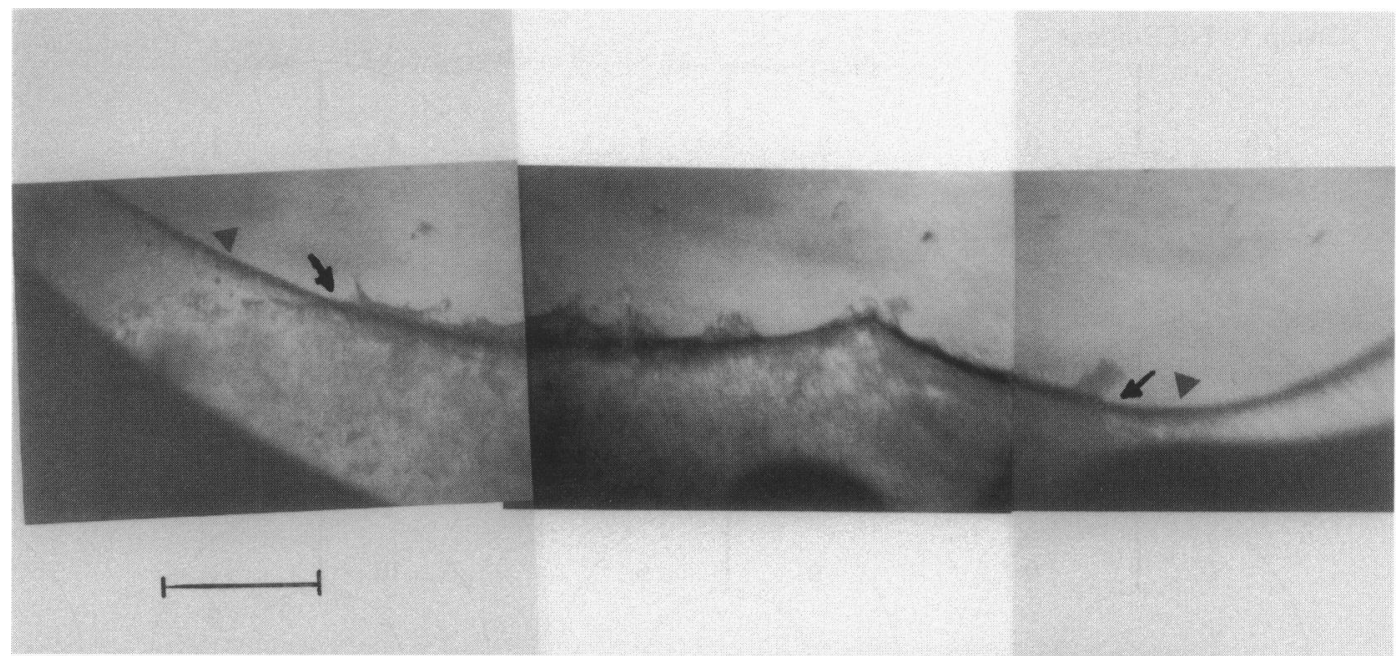

Figure 3 Specular photomontage showing lens epithelial cell proliferation restricted to the region of anterior capsule-implant contact (in between the arrows). The anterior capsule margin is marked (arrowheads). Bar $=400 \mu \mathrm{m}$.

median, 25th, and 75th percentiles. Differences in density scores between the groups were tested with the Mann-Whitney $U$ test. The association of region of anterior capsule-implant touch and region of anterior capsular opacification with lens epithelial cell density and location was tested with the $\chi^{2}$ test. Correlations between lens epithelial cell density grades and anterior chamber flare measurements were tested separately within each of the three study groups using analysis of variance (ANOVA).

\section{Results}

Lens epithelial cell proliferation occurred on the anterior surface of the intraocular lens in all three groups, either in the form of a continuous rim of cells from the anterior capsular edge or as flat cells $(80-120 \mu \mathrm{m})$ with short stubby

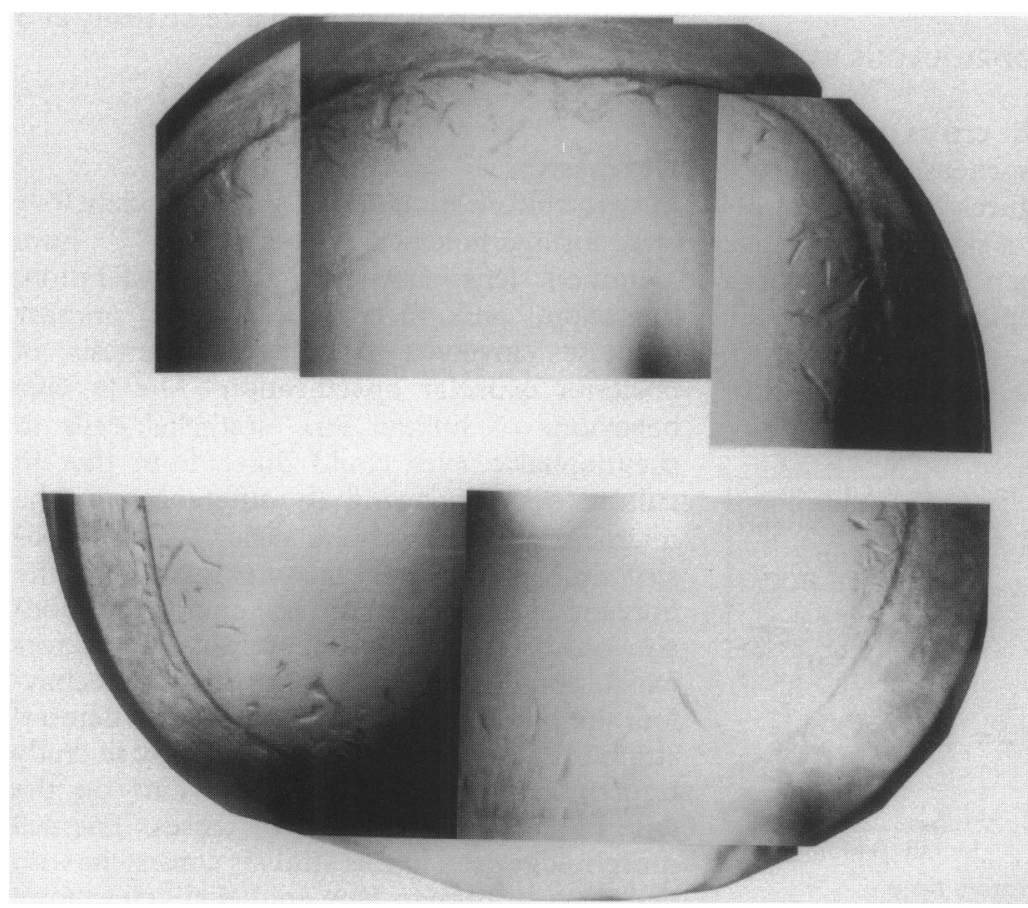

Figure 4 Specular photomontage showing a ring of lens epithelial cells inside the anterior capsular rim. This appearance was only seen in groups 2 and 3 (capsulorhexis with ECCE and capsulorhexis with phacoemulsification) if the whole of the anterior capsular rim came in contact with the anterior surface of the implant. processes the tips of which showed interference patterns in some cases (Fig 2). This proliferation seemed to be restricted to and initiated by the free edge of the anterior capsule coming in contact with the implant optic surface (Fig 3). In group 2 and 3 cases, if the whole rim of anterior capsule came in contact with the implant optic, the lens epithelial cells were seen arranged in a ring, around the anterior capsule rim (Fig 4). Anterior capsule-implant optic contact was seen from 1 week onwards; by 1 month almost all cases showed this contact. Anterior capsular opacification was evident in a small number of cases at 1 week; by 3 months anterior capsular opacification was seen in almost all cases.

\section{TOPOGRAPHY}

The topography maps for the three groups are shown in Figure 5. Lens epithelial cells were almost exclusively seen on the peripheral region of the implant in all study patients. The region of anterior capsule-implant optic contact had a significant correlation with the region occupied by lens epithelial cells in all study groups at 1 week (group $1, \mathrm{p}<0.01$; group $2, \mathrm{p}<0.0000$; group $3, \mathrm{p}<0.01$ ) and at 1 month in group 2 only $(\mathrm{p}<0.0032)$.

\section{DENSITY}

The median, 25th, and 75th percentile lens epithelial cell density grades in the three groups are shown in Figure 6. Lens epithelial cells were seen on the implant surface from 1 week onwards, reaching a peak density at 1 month in all groups. Compared with groups 1 and 3, lens epithelial cell density was significantly higher in group 2 at 1 week $(p<0.001)$ and 3 months $(p<0 \cdot 0000)$. No significant differences were found between groups 1 and 3. Lens epithelial cell density had a significant positive relation with increasing anterior capsule-implant optic contact at 1 week in all groups (group 1, $\mathrm{p}<0.03$; group $2, \mathrm{p}<0.0002$; group $3, \mathrm{p}<0.02)$ and at 1 month $(p<0.013)$ and 3 months $(p<0.006)$ in group 2 cases only. A significant negative association with increasing anterior 
Group 1 - ECCE-linear

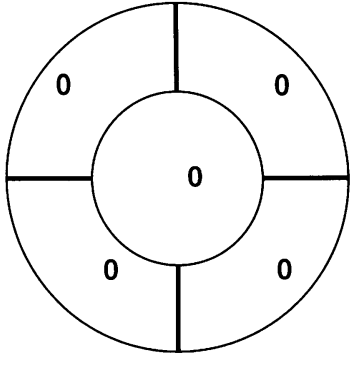

1 Day

Group 2 - ECCE-CCC

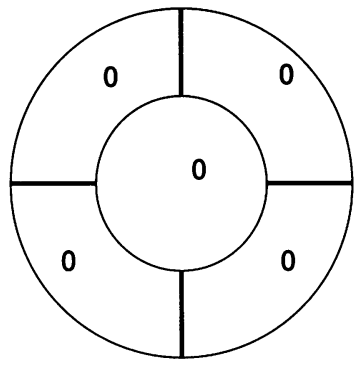

1 Day

Group 3 - Phaco-CCC

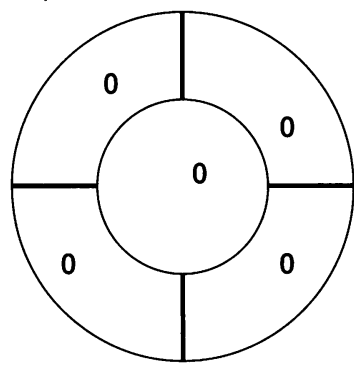

1 Day

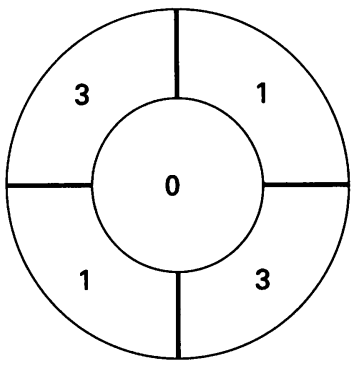

1 Week

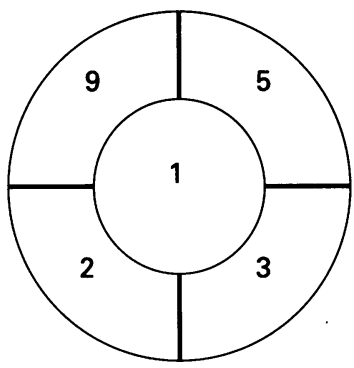

1 Week

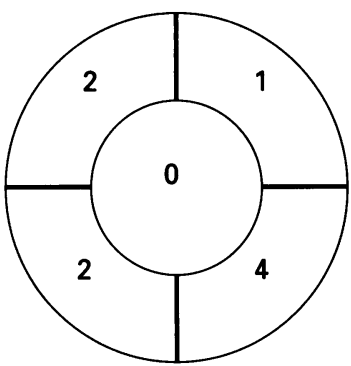

1 Week

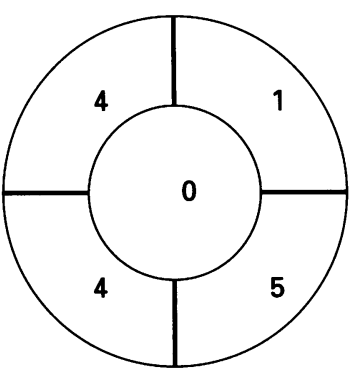

1 Month

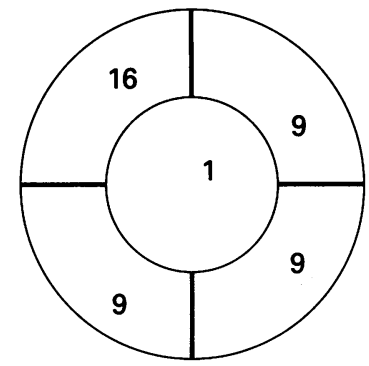

1 Month

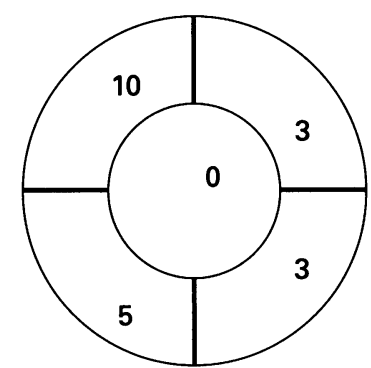

1 Month

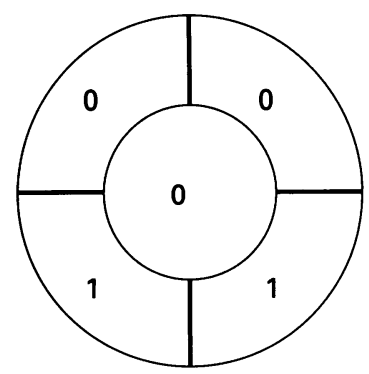

3 Months

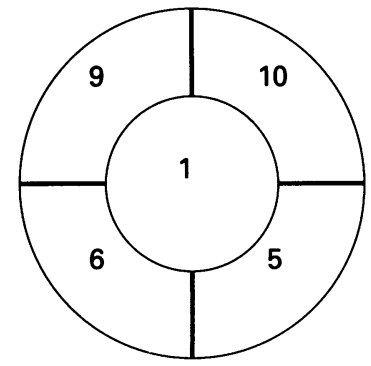

3 Months

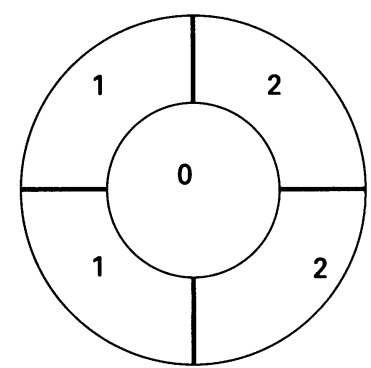

3 Months

Figure 5 The location of lens epithelial cells on the implant surface in the three groups. The numbers indicate the number of eyes with cells present in that location.

capsular opacification was found at 3 months $(p<0.02)$ in group 2 only.

CORRELATIONS WITH BLOOD-AQUEOUS BARRIER DISRUPTION

The mean and standard errors of anterior chamber flare and cells measurements are plotted against time in Figures 7 and 8, respectively. In groups 2 and 3, a significant positive relation was found between anterior chamber flare at day 1 and lens epithelial cell density at 3 months (group 2, $<<0.02$; group 3 , $\mathrm{p}<0.000$ ). In group 1 , a significant positive

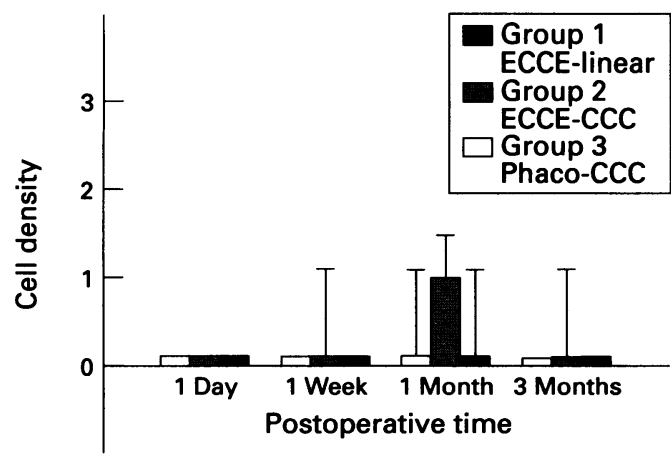

Figure 6 Median (bars) and 75th percentile (error bars) lens epithelial cell density grades $(0-3$ as per criteria in Table 1) in the three groups. relation was found between anterior chamber flare at 1 week and lens epithelial cell density at 1 month $(\mathrm{p}<0.05)$ and anterior chamber flare at 3 months and lens epithelial cell density at 3 months $(p<0 \cdot 05)$.

\section{Discussion}

In vitro culture studies, ${ }^{14-18}$ animal models, ${ }^{19-21}$ and histopathological observations ${ }^{2627}$ have identified lens epithelial cell proliferation, migration, and metaplasia as the primary processes involved in the pathogenesis of posterior capsular opacification. The in vivo behaviour of human lens epithelial cells in pseudophakic eyes could differ from that in culture systems owing to differences in the microenvironment of the cells. Wound construction in the lens, factors related to the implant biomaterial, and postoperative bloodaqueous barrier disruption are potential factors which could modify lens epithelial cell behaviour in pseudophakic eyes. We have demonstrated the use of specular microscopy to study human lens epithelial cell behaviour on the anterior surface of intraocular lenses. The cell morphology seen in this study is consistent with that seen in human lens epithelial cell culture studies 14171826 and histopathological observations on human tissue. ${ }^{28}$

Our results show that lens epithelial cell 


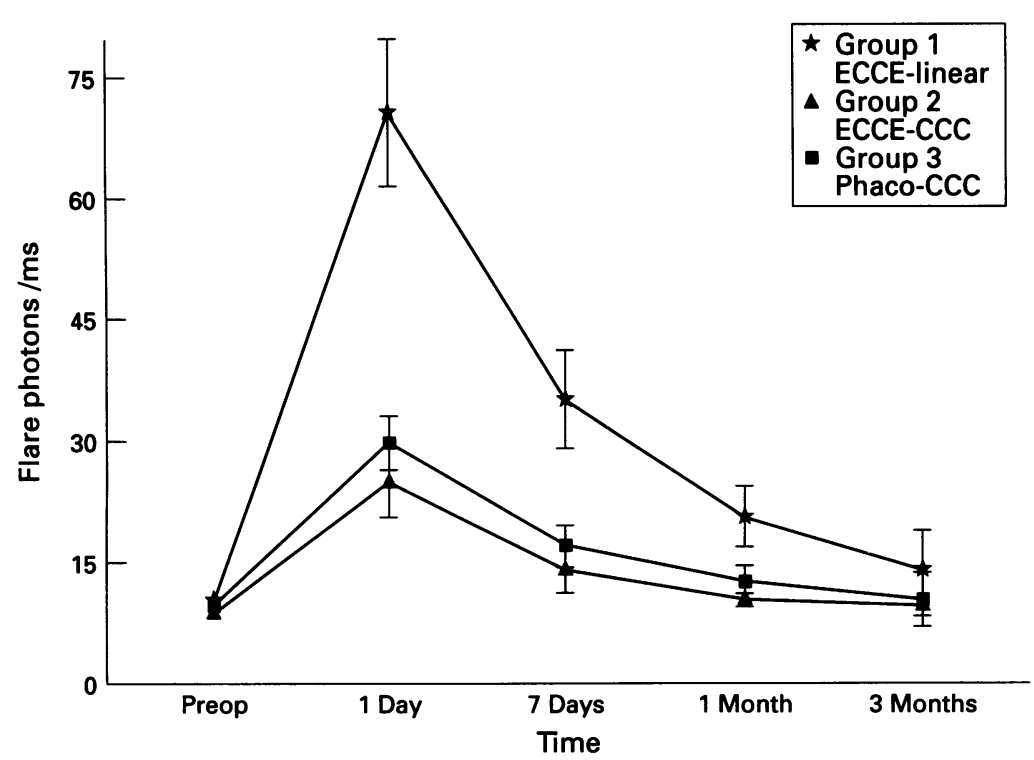

Figure 7 Mean and standard errors of anterior chamber laser flare measurements in the three groups. proliferation occurs on the anterior surface of PMMA implants irrespective of surgical technique. This proliferation is seen as early as 1 week and by 3 months the cells disappear. The region of the anterior capsule comes in contact with the implant opacifies as a result of lens epithelial cell metaplasia. ${ }^{172829}$ Lens epithelial cell proliferation seen in our cases was initiated by anterior capsule-implant contact and decreased as the anterior capsule in contact with the implant opacified. The topography and cell density had a significant positive correlation with the region of anterior capsuleimplant contact and a negative correlation with anterior capsular opacification. These findings suggest that on contact with the implant surface lens epithelial cells from the anterior capsular margin start proliferating and migrating on to the implant surface. These cells initially proliferate in a continuous sheet which later breaks up. The onset of anterior capsular opacification seems to coincide with a decrease

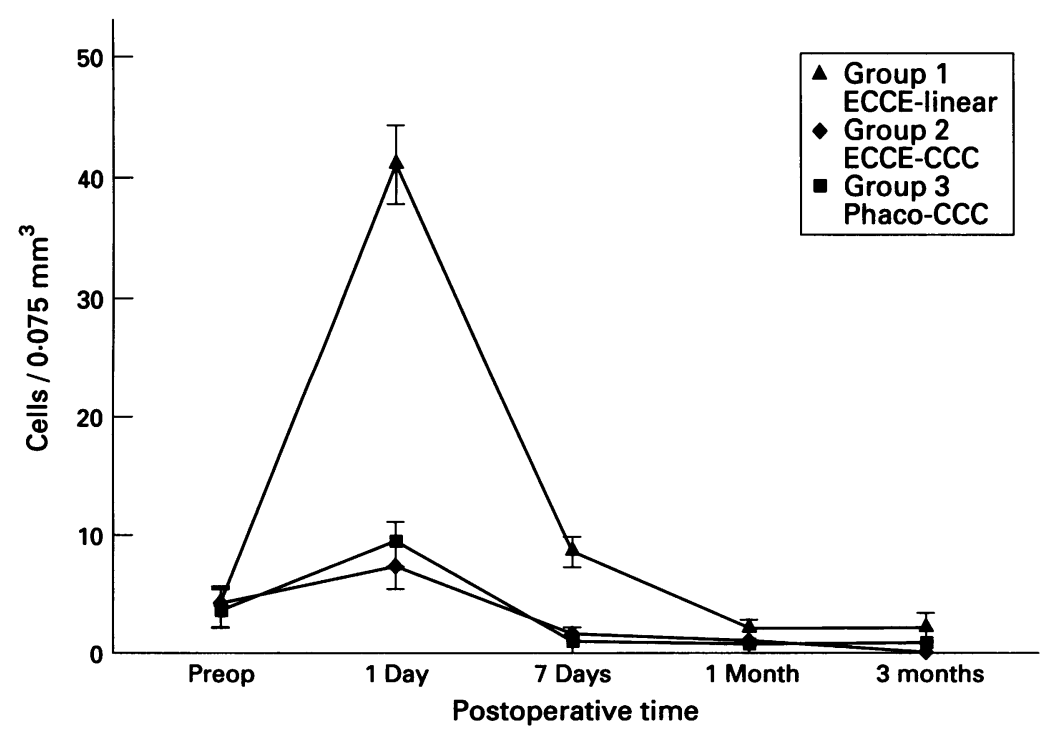

Figure 8 Mean and standard errors of anterior chamber laser cells measurements in the three groups. in lens epithelial cell migration on to the anterior implant surface. The differences in cell density seen between the study groups can be explained by the differences in the potential regions of contact between the anterior capsule and the implant optic. Eyes in group 2 with a larger capsulorhexis and a larger optic diameter showed a higher lens epithelial cell density compared with group 3 (smaller capsulorhexis and smaller implant optic) and group 1 (free capsular flaps which rolled over or under themselves).

Lens epithelial cells were almost exclusively seen on the peripheral parts of the implant and never covered the whole of the implant surface in a single continuous sheet in any eye. This is contrary to the findings from culture studies ${ }^{141718}$ where human lens epithelial cells can be grown in confluent sheets on PMMA surfaces and maintained in culture for more than a year. ${ }^{14}$ Alterations to the PMMA surface in vivo by protein adsorption changing the surface chemistry, qualitative and quantitative differences in humoral factors between in vitro culture medium and the aqueous humour in postoperative pseudophakic eyes are likely to explain these differences. The morphology of lens epithelial cells cultured on to surface modified PMMA has been shown to differ from that of virgin PMMA. ${ }^{30}$ Rabbit, $^{31}$ bovine, and porcine ${ }^{32}$ lens epithelial cells have been shown to adhere more to PMMA surfaces than Silicone and HEMA surfaces.

The correlation between postoperative blood-aqueous barrier breakdown and the later proliferation of lens epithelial cells found in all groups suggests that postoperative bloodaqueous barrier breakdown releases factors into the aqueous which stimulate lens epithelial cell proliferation and migration. This would corroborate clinical observations of a higher incidence of posterior capsular opacification in eyes with uveitis undergoing cataract surgery.

In vitro studies have demonstrated that fibronectin, laminin, type IV collagen, ${ }^{16}$ and fibroblast growth factor ${ }^{15}$ stimulate lens epithelial cell proliferation and migration. Fibronectin is not found in significant quantities in adult human lens capsule ${ }^{33} 34$ but fibronectin immunoreactivity has been demonstrated in the acellular proteinaceous membrane on explanted intraocular lenses ${ }^{35}{ }^{36}$ as well as on macrophages and giant cells found on the anterior surface of intraocular lenses..$^{37} 38$ It has been postulated that fibronectin of serum origin as a result of postoperative blood-aqueous barrier damage could play an important role in lens epithelial cell proliferation and migration. ${ }^{1639}$ Our findings would support this postulate though the contribution of other factors cannot be ruled out.

The relation between lens epithelial cell proliferation on the anterior implant surface and on the posterior capsule is unknown. The environment at the posterior implant interface differs from that at the anterior implant interface. Posterior capsular opacification occurs as a result of lens epithelial cell proliferation on a 
physiological substrate (posterior capsule) to which the implant is apposed to a varying degree with limited access to the aqueous while proliferation at the anterior interface occurs on the implant surface which is exposed to the aqueous. Despite these differences in the environment it is not unlikely that similar mechanisms may apply. We propose that human lens epithelial cell proliferation and migration in vivo are initiated by loss of contact inhibition as a result of surgical trauma and humoral factors released into the aqueous as a result of postoperative blood-aqueous barrier breakdown. These processes would be modified by implant biomaterial properties to a varying extent depending on the anatomical relations of the implant to the anterior and posterior lens capsule. Developing strategies based on these factors could enable us to modulate in vivo lens epithelial cell behaviour and prevent posterior capsular opacification, which, to date, remains the commonest complication of modern cataract surgery.

This paper is in part contribution towards the degree of Doctor of Philosophy at the University of London for M Pande.

Presented in part at the ARVO annual meeting, Sarasota 1994.

Milind V Pande was an Iris Fund Research fellow supported by the Iris Fund For Prevention of Blindness. This study was supported by charitable funds from The Iris Fund, The Sta Foundation and The Andrew Wilson Trust.

1 Fagerholm P, Fitzsimmons T, Harfstrand A, Schenholm M Reactive formation of hyaluronic acid after small and large lens injury. Acta Ophthalmol 1992; 205: 58-64.

2 Nishi $O$, Nishi $K$. Intercapsular cataract surgery with lens epithelial cell removal. Part III: Long term follow-up of posterior capsular opacification. $\mathcal{f}$ Cataract Refract Surg posterior capsular

3 Nishi O, Nishi K, Hikida M. Removal of lens epithelial cells following loosening of the junctional complex. $f$ Cataract Refract Surg 1993; 19: 56-61.

4 Nishi O. Removal of lens epithelial cells by ultrasound in endocapsular surgery. Ophthalmic Surg 1987; 18: 577-80.

5 Hansen TE, Otland N, Corydon L. Posterior capsule fibrosis and intraocular lens design. $\mathcal{F}$ Cataract Refract Surg 1988; 14: 383-86

6 Martin RG, Sanders DR, Souchek J, Raanan MG, DeLuca $M$. Effect of posterior chamber IOL design and surgical placement upon postoperative outcome. $\mathcal{f}$ Cataract Refract placement upon postope

7 Tetz M, O'Morchoe D, Gwin T, Willbrandt TH, Solomon $\mathrm{KD}$, Hansen SO, et al. Posterior capsular opacification and intraocular lens decentration. Part II: Experimenta findings on a prototype circular intraocular lens design. f Cataract Refract Surg 1988; 14: 614-23.

8 Davis PL, Hill P, Coffey A. Convex posterior PMMA implants: do PMMA vs prolene haptics alter capsular opacity? Eur F Implant Refract Surg 1991; 3: 127-30.

9 Sterling $S$, Wood T. Effect of intraocular lens convexity on posterior capsular opacification. $\mathcal{f}$ Cataract Refract Surg 1986; 12: 655-7.

10 Born CP, Ryan DK. Effect of intraocular lens optic design on posterior capsular opacification. $\mathcal{F}$ Cataract Refract Surg 1990; 16: 188-92.

11 Davis PL, Hill P. Inhibition of capsule opacification by convex surface posterior three-piece all PMMA C-loo lenses: a fellow eye and same lens study. Eur $\mathcal{f}$ Implant Refract Surg 1989; 1: 237-40.

12 Apple DJ, Mamalis N, Loftfield K, Googe JM, Novak L Norman DK, et al. Complications of intraocular lenses. A historical and histopathological review. Surv Ophthalmol 1984; 29: 1-54.

13 Wilhelmus KR, Emery JM. Posterior capsular opacification following phacoemulsification. Ophthalmic Surg 1981; 11: 264-7.
14 Arita T, Murata Y, Lin LR, Tsuji T, Reddy VN. Synthesis of lens capsule in long term culture of human lens epithelial cells. Invest Ophthalmol Vis Sci 1993; 34: 355-62.

15 Lovicu FJ, McAvoy JW. Localization of acidic fibroblast growth factor, basic fibroblast growth factor and heparan sulphate proteoglycan in rat lens: implications for lens polarity and growth patterns. Invest Ophthalmol Vis Sci polarity and growth

16 Olivero DK, Furcht LT. Type IV collagen, laminin and fibronectin promote the adhesion and migration of rabbit ens epithelial cells in vitro. Invest Ophthalmol Vis Sci 1993; 34: 2825-34.

17 Ohara K, Itakura K, Ibaraki N. Anterior capsule opacification: a cell culture model. Acta Ophthalmol 1992; 205: 29-33.

18 Nishi K, Nishi O. Tissue culture of human lens epithelial cells. Part II. Suppressive effect of diclofenac sodium on their proliferation and metaplasia. Nippon Ganka Gakkai Zasshi 1991; 95: 581-90.

19 Cobo LH, Ohsawa E, Chandler D, Arguello R, George F. Pathogenesis of capsular opacification after extracapsular cataract extraction. An animal model. Ophthalmology 1984; 91: 857-63.

20 Lundgren B, Jonsson E, Rolfsen W. Secondary cataract. An in vivo model for studies on secondary cataract in rabbits. Acta Ophthalmol 1992; 205: 25-8.

21 Ayaki M, Kyu N. Histopathologic study of after-cataract in pseudophakic rabbit eye using in-the-bag fixation. Nippon Ganka Gakkai Zasshi 1990; 94: 559-65.

22 Ohara K. Biomicroscopy of surface deposits resembling foreign body giant cells on implanted intraocular lenses. Am f Ophthalmol 1985; 99: 304-11.

23 Sievers $\mathrm{H}$, Von Domarus D. Foreign body reaction against intraocular lenses. Am $\mathcal{f}$ Ophthalmol 1984; 97: 743-51.

24 Wenzel M, Reim M, Heinze M, Böcking A. Cellular invasion on the surface of intraocular lenses. In vivo cytological observations following lens implantation. Graefes Arch Clin Exp Ophthalmol 1988; 226: 449-54.

25 Pande M, Spalton DJ, Marshall J. Continuous curvilinear capsulorhexis and implant biocompatibility. $\mathcal{f}$ Cataract Refract Surg (in press)

26 Frezzotti R, Caporrosi A, Mastrangelo D, Hadjistilianou T, Tosi $\mathrm{P}$, Cintorino M, et al. Pathogenesis of posterior capsular opacification. Part II: Histopathological and in vitro culture findings. F Cataract Refract Surg 1990; 16: 353-60.

27 McDonnell PJ, Zarbin MA, Green WR. Posterior capsular opacification in pseudophakic eyes. Ophthalmology 1983; 90: 1548-53.

28 Hara T, Azuma N, Chiba K, Ueda Y, Hara T. Anterior capsular opacification after endocapsular cataract surgery. Ophthalmic Surg 1992; 23: 94-8.

29 Hara T, Hara T, Kojima M, Nakaizumi H, Yamamura T, Sasaki K. Specular microscopy of the anterior lens capsule after endocapsular lens implantation. $\mathcal{f}$ Cataract Refract Surg 1988; 14: 533-40.

30 Ichijima $H$, Kobayashi $H$, Ikada $Y$. In vitro evaluation of biocompatibility of surface modified poly(methyl methacrylate) plate with rabbit lens epithelial cells. $\mathscr{f}$ Cataract Refract Surg 1992; 18: 395-401.

31 Cunanan CM, Tarbaux NM, Knight PM. Surface properties of intraocular lens materials and their influence on in vitro cell adhesion. I Cataract Refract Surg 1991; 17: 767-73.

32 Humphry RC, Ball SP, Brammall JE, Conn SJ, Rich WJ. Lens epithelial cells adhere less to HEMA than to PMMA intraocular lenses. Eye 1991; 5: 66-9.

33 Parmigiani CM, McAvoy JW. The roles of laminin and fibronectin in the development of the lens capsule. Curr Eye Res 1991; 10: 501-11.

34 Hettlich HJ, Wenzel M, Janssen M, Mittermayer C. Immunohistochemical studies on the human lens capsule. Fortschr Ophthalmol 1990; 87: 147-9.

35 Boyd W, Peiffer DVM, Siegal G, Eifrig DE. Fibronectin as a component of pseudophakic acellular membranes. $\mathcal{f}$ Cataract Refract Surg 1992; 18: 180-3.

36 Sakamoto T, Ishibashi T, Sugai S, Ohnishi Y, Fukushima $\mathbf{M}$, Sueishi K. Immunohistochemical study of the surface membrane on a intra-ocular lens. Nippon Ganka Gakkai Zasshi 1990; 94: 1074-8.

37 Kanagawa R, Saika S, Ohmi S, Tamura M, Nakao T. Presence and distribution of fibronectin on the surface of implanted intraocular lenses in rabbits. Graefes Arch Clin Exp Ophthalmol 1990; 228: 398-400.

38 Saika S, Uenoyama S, Kanagawa R, Tamura M, Uenoyama $K$. Phagocytosis and fibronectin of cells observed on intraocular lenses. Fpn $\mathcal{f}$ Ophthalmol 1992; 36: 184-91.

39 Kappelhof JP, Pamaeyer JH, De Jong PTVM, Jongkind JF, Vrensen GFJM. The proteinaceous coating and cytology
of implant lenses in rabbits. Am 7 Ophthalmol 1986; 102: 750-8. 